\title{
Identification of Geochemical Anomalies Using Fractal Analysis in Janja Area, SE Iran
}

\author{
Ali Akbar Daya, and Marzieh Hosseini-Nasab
}

\begin{abstract}
In this study, the Concentration-Area (C-A) fractal model was used for determining the geochemical concentrations in Janja, SE Iran. Eight elements ( $\mathrm{Au}, \mathrm{Cu}, \mathrm{Mn}, \mathrm{Zn}, \mathrm{Fe}, \mathrm{As}, \mathrm{Mo}$, and $\mathrm{Pb}$ ) from 300 stream sediment samples were used to identify geochemical anomalies. The geochemical maps obtained from fractal modelling showed that geochemical anomalies for copper and gold are located in the north, NW and center of the study area. Comparing the anomalies maps of the elements showed a correlation between elements of gold, copper, molybdenum and iron in the region. Also, a negative correlation was determined between arsenic with gold and copper elements and there wasn't any correlation between the gold and copper elements of region with manganese, lead and zinc.
\end{abstract}

Index Terms-Geochemistry; Anomaly separation; Concentration - Area (C-A) fractal model; Janja.

\section{INTRODUCTION}

The regional geochemical exploration is important in order to reduce the wide area to small areas, reduce the costs and risks of investment. One of the most important parts of regional geochemical exploration is the processing of data of sampling operations and laboratory analysis, in this way there are various methods. In this study, the geochemical exploration data related to stream sediments of Janja region were processed. The detection of data outliers and unusual data structures (anomalies) is one of the most important tasks in the statistical analysis (Filzmoser et al., 2005; Garrett, 1989; Rousseeuw and Leroy, 1987). Traditionally, despite the fact that geochemistry data sets are almost always multivariate, outliers are most frequently sought for each single variable in a given data set (Filzmoser et al., 2005). In the current study concentration area fractal model was used to delineate anomalies from background in Janja region, SE Iran.

\section{II.FRACTAL MODEL}

Based on Euclidean geometry, the around physical objects can be defined as shapes without dimension, one, two, and three-dimension. In Euclidean geometry, the dimension can be an integer such as one, two, three, and so on; but there are some phenomena in the world that cannot be justified in the framework of Euclidean geometry. For example, there is no possibility to determine some phenomena or events, such as the roughness of the surface of the mountains, shape of the coastline

Ali Akbar Daya, and Marzieh Hosseini-Nasab are with university of Sistan and Baluchestan, Department of Mining, Daneshgah street, Zahedan, Iran.

Corresponding Author Email: aliakbardaya@eng.usb.ac.ir and many other natural objects and events by integer; also, the coordinate axes which are defined for describing these phenomena and events may not be perpendicular (Dimiri, 2000).

According to a non-Euclidean viewpoint, some phenomena and events can be considered as a Rational number in some cases. In these cases, the dimension can be changed from zero to one, from one to two or more. This viewpoint was the basis of the Fractal Geometry which was established by Mandelbrot (1983).

Theoretical Fractal studies and recent studies in earth science show that some geological processes such as mineralization, sedimentation, deposition, volcanic eruptions, morphology, and others have the characteristics of self-resemblance. Therefore, it can be found some evidences for fractal dimension from these cases (Cheng 1999).

Cheng et al. (1994) proposed the concentration-area (C-A) fractal model, which may be used to define the geochemical background and different anomalies, as the following form.

$$
A(\rho \leq v) \infty \rho^{-a 1 ;} \quad A(\rho \geq v) \infty \rho^{-a 2}
$$

Where $A(\rho)$ denotes the area with concentration values greater than the contour value $\rho$; $v$ represents the threshold; and a1 and a2 are characteristic exponents. The two approaches used to calculateA( $\rho)$ by Cheng et al. (1994) were: (1) The A( $\rho)$ which is the area enclosed by contour level $\rho$ on a geochemical contour map resulting from interpolation of the original data using a weighted moving average method, and (2) A( $\rho)$ that are the values obtained by box counting of original elemental concentration values. By box counting, one superimposes grid with cells on the study region. The area $A(\rho)$ for a given $\rho$ is equal to the number of cells multiplied by cell area with concentration values greater than $\rho$. The breaks between straight-line segments on this plot and the corresponding values of $\rho$ have been used as cut-offs to separate geochemical values into different components, at the same time representing different causal factors, such as lithological differences and geochemical processes (Heidari et al., 2013; Daya, 2015a; Daya, 2015b). Factors such as mineralizing events, surficial geochemical element concentrations and surficial weathering are important to be considered (Goncalves et al., 2001; Lima et al., 2003; Daya, 2015a; Daya, 2015b; Daya and Afzal., 2015; Afzal et al., 2010; Heidari at al., 2013). 


\section{GeOlogical SETting OF JANJA AREA}

The studied area is near the Sefidabeh, a district of Poshtab of Zabol city. The oldest rocks of the region are sedimentary rocks with flyschfacies largely dispersed in the region. Igneous rocks of the study area are mainly in the form of dykes from the trend of East - West and North East - South West which penetrated in sedimentary rocks and they have changed the general trend of the rocks.

The region has general east-west and NE-SW trends structures. These trends followed by the inclined collision of
Lut plate with Neh complex at the end of Eocene, continue the compressing movements; and at the end of Oligocene, the pressure, as sliding-stretching movements, has appeared in line with some old breaks and a much younger coupled system. Upper Miocene right turning tectonics affecting of old systems of the area which are related to the closure of east Flysch basin of Iran (Eocene-Oligocene) creates suitable stretching spaces for discharging lava. Dikes in the studied area are visible in form of altered and non-altered porphyritic in texture (Graffis et al., 1977:1978).
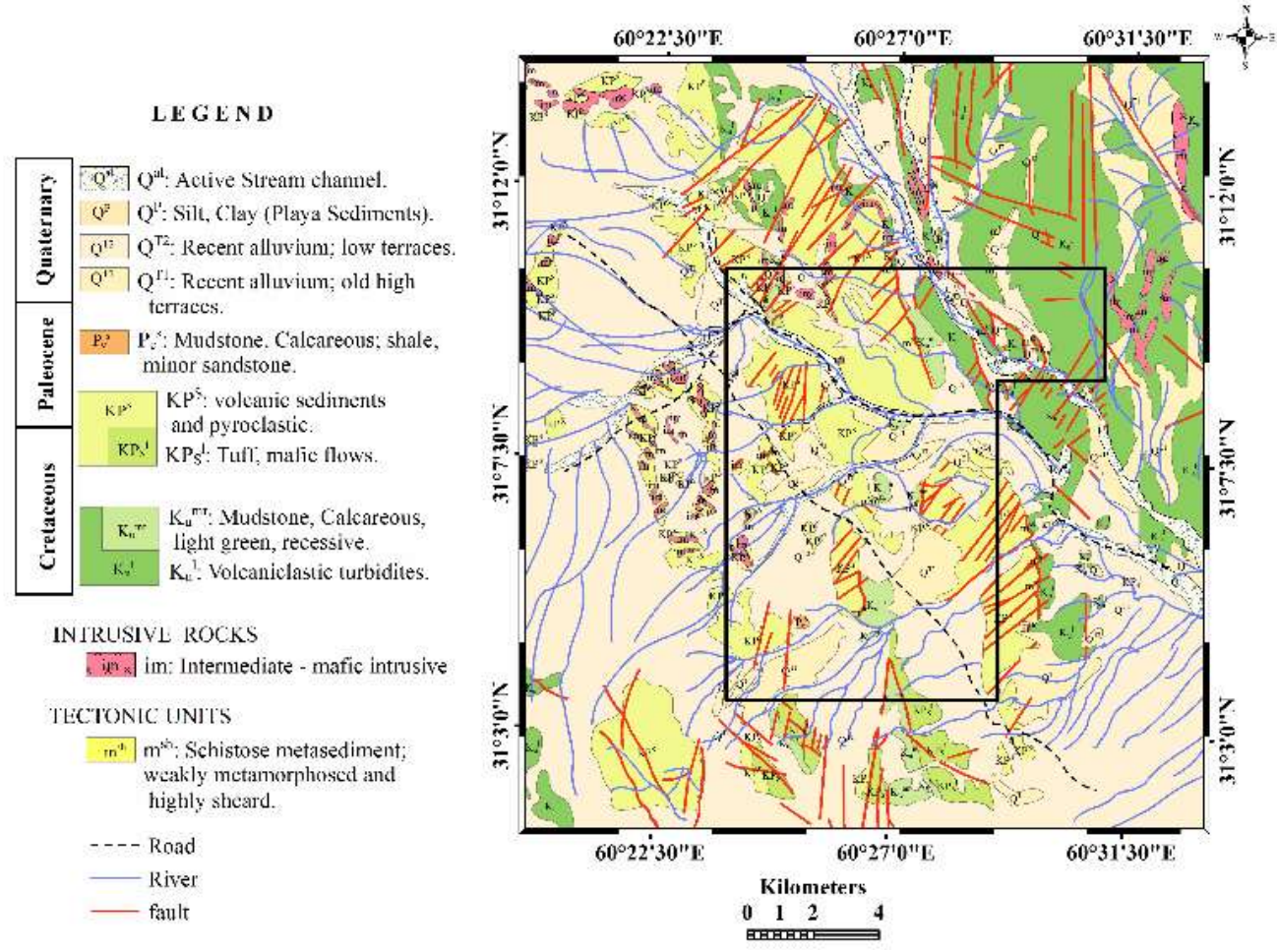

Fig.1: Geological map of Janja region with the scale of 1/20000

The main minerals of rocks in the region in manual sample are amphibole (hornblende) and plagioclase (Fig.1). In addition to the main mineral in microscopic levels, there are secondary minerals of epidote, chlorite, calcite and opaque minerals. The results of the modal mineralogy studies and chemical analysis showed that these rocks are much more granodiorite to diorite in terms of lithological composition and they are in Calc-alkaline range in terms of magmatic series.

Field investigations and laboratory studies that were done on igneous and metamorphic rocks showed that the studied region didn't have a lithological diversity. Igneous rocks are diorite dikes and sedimentary rocks include shale, sandstone and carbonate rocks (limestone and mudstone) which have undergone a weak transformation and heterology due to penetration dikes. These rocks along with dikes are form the highlands of this region. The metamorphic rocks in Janja region include slate and hornfels. It seems that protoliths of these rocks were carbonate shale and limestone which were undergone a weak transformation.

It seems that in the last stages of the magmatic dikes cooling, hydrothermal fluids get out and at the time of penetrating the rock walls, it leads to the formation of minerals in them.

Potential mineralization in the area is done in two ways. The main form of mineralization in the area is associated with the transformation and alteration. The effect of this process include transforming the rocks, creating Calc-silicate rocks containing garnet, propillite alteration, making rocks Siliceous, and the presence of sulfur minerals such as pyrite and chalcopyrite. The mineralization occurred as micro-riche fillings and the formation of Iron oxides with copper carbonates (malachite and azurite) which were local and especially on the periphery of the main mineralization veinlets in form of low zones, show this kind of Surface mineralization (Thomson and Howarth, 1978).

\section{SAMPLING, MODELING AND DATA ANALYSIS}

In order to determine the area with the most anomalies, the concentration of 8 elements of $\mathrm{Au}, \mathrm{Cu}, \mathrm{Mn}, \mathrm{Zn}, \mathrm{Fe}, \mathrm{As}, \mathrm{Mo}$, and $\mathrm{Pb}$ in 300 points of region's stream sediments were measured and recorded. Figure 3 shows the location of sampling points in 
the studied region.

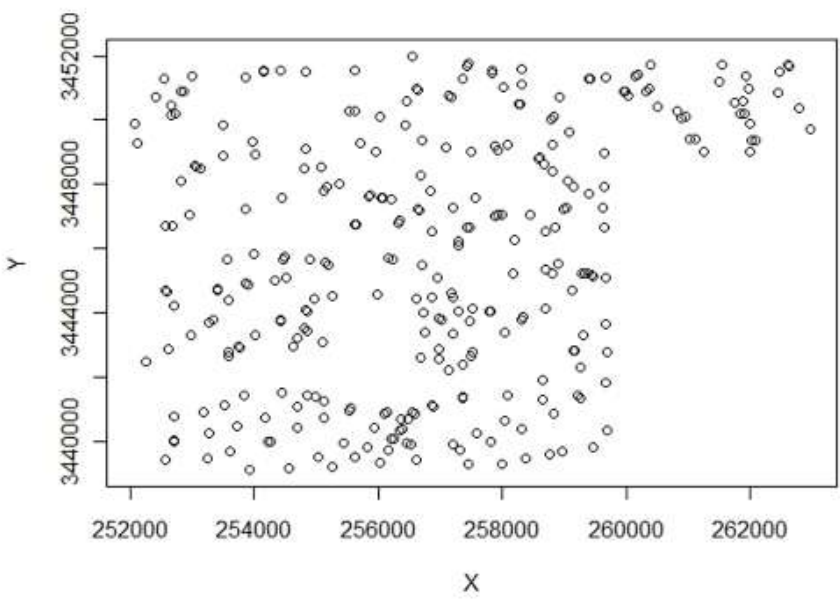

Fig.2: The location of stream sediments samples in Janja region
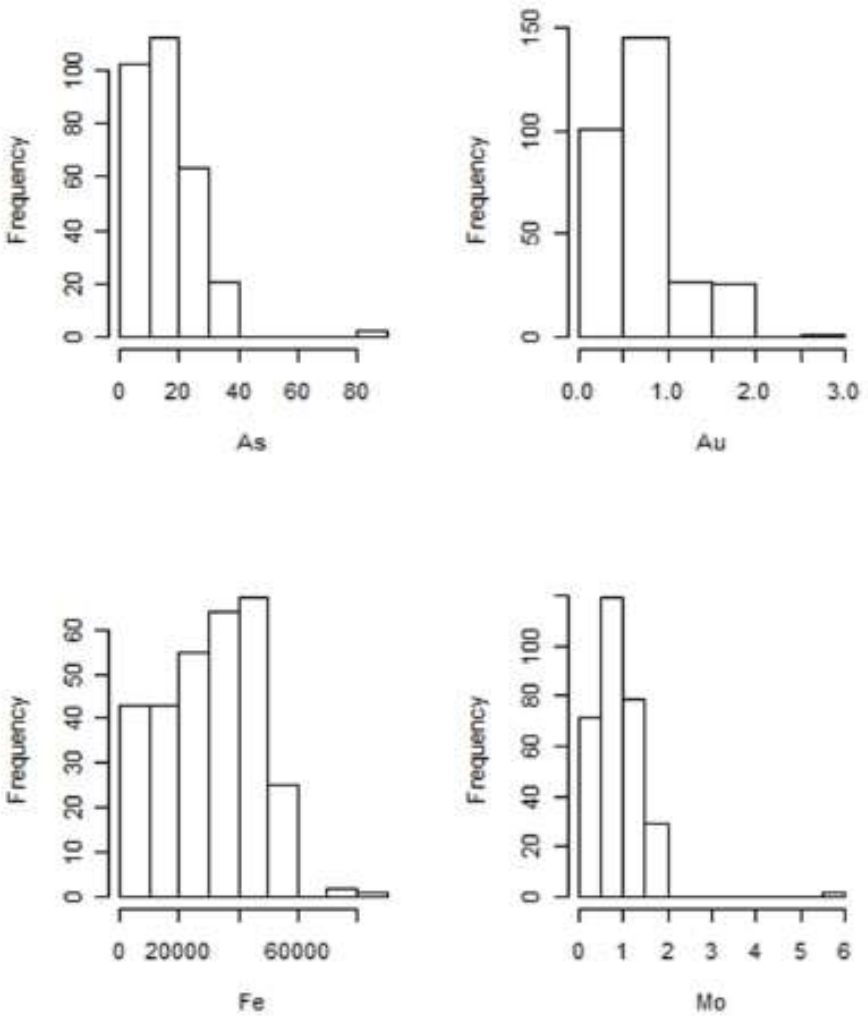

The statistical investigation of collected data of stream sediment in the region in estimating and identifying the statistical features of the raw data, particularly the nature of their distribution function, help in better analysis of data resulting from estimation. Therefore, identifying the statistical variables of society including mean, variance, coefficient of variation, and in particular the skewness which implies on being normal or abnormal function of data distribution will be helpful (Jimenez-Espinosa et al. 1993). Statistical analysis was carried out by R Statistical Software (Foundation for Statistical Computing, Vienna, Austria).In table 1, a summary of descriptive statistical observations is stated. Among all these factors, the shape of distribution function and its deviation from the normal distribution and the possibility of converting data to the normal distribution in the estimation process is very important (Jimenez-Espinosa et al. 1993). Therefore, it is necessary to draw a diagram and frequency distribution of data for these variables (Fig.3).

In Figure 3, to describe the data, histogram of variables is shown:
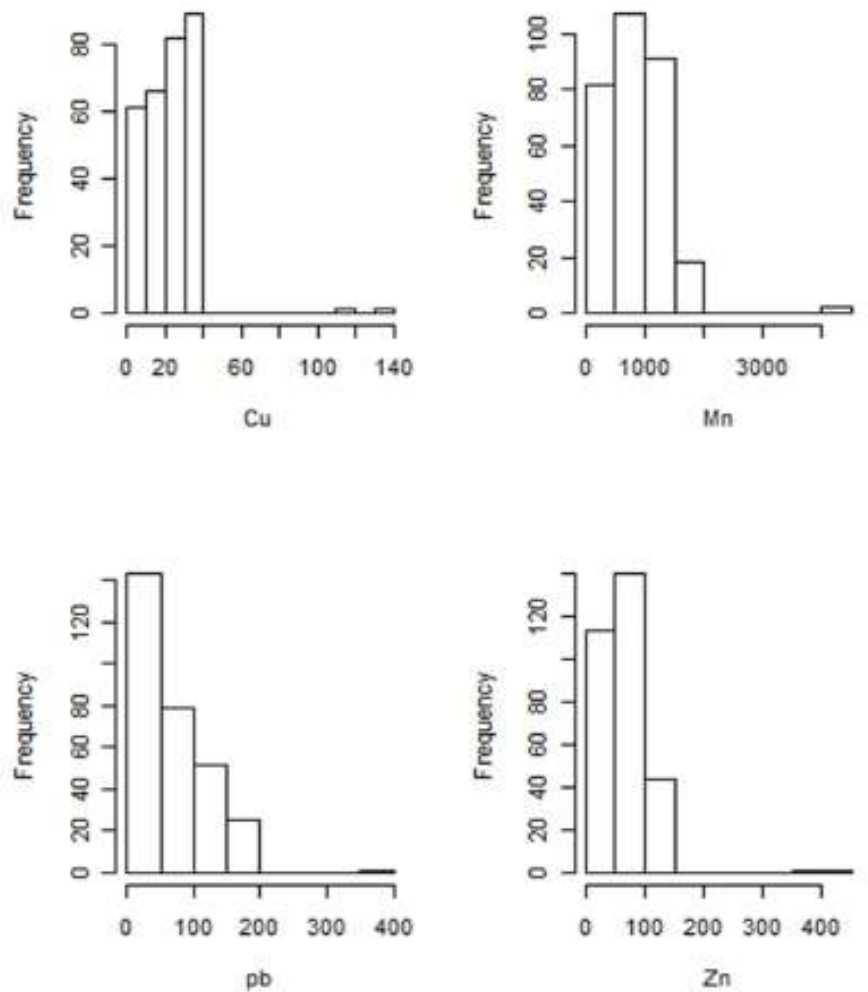

Fig.3. Histogram of $\mathrm{As}, \mathrm{Au}, \mathrm{Cu}, \mathrm{Mn}, \mathrm{Fe}, \mathrm{Mo}, \mathrm{Pb}$ and $\mathrm{Zn}$ in the stream sediment samples from Janja region

To check the process, the diagram of data balance was plotted. The contour line is a curve that connects all the points with the same concentration. The reason of drawing the contour line of data is to see whether the mean of random field is constant or not. Figure 4 shows the contour lines curve for 8 studied elements. Since there isn't any special pattern in these figures, the mean of random field is considered as fixed. Bear in mind that if the mean of random field is fixed, the normal kriging can be used.

\section{V.RESULTS AND DISCUSSION}

Concentration-area relations were computed by assigning an area of influence to each sampled point and summing all elemental areas whose concentration lies below a given value. 

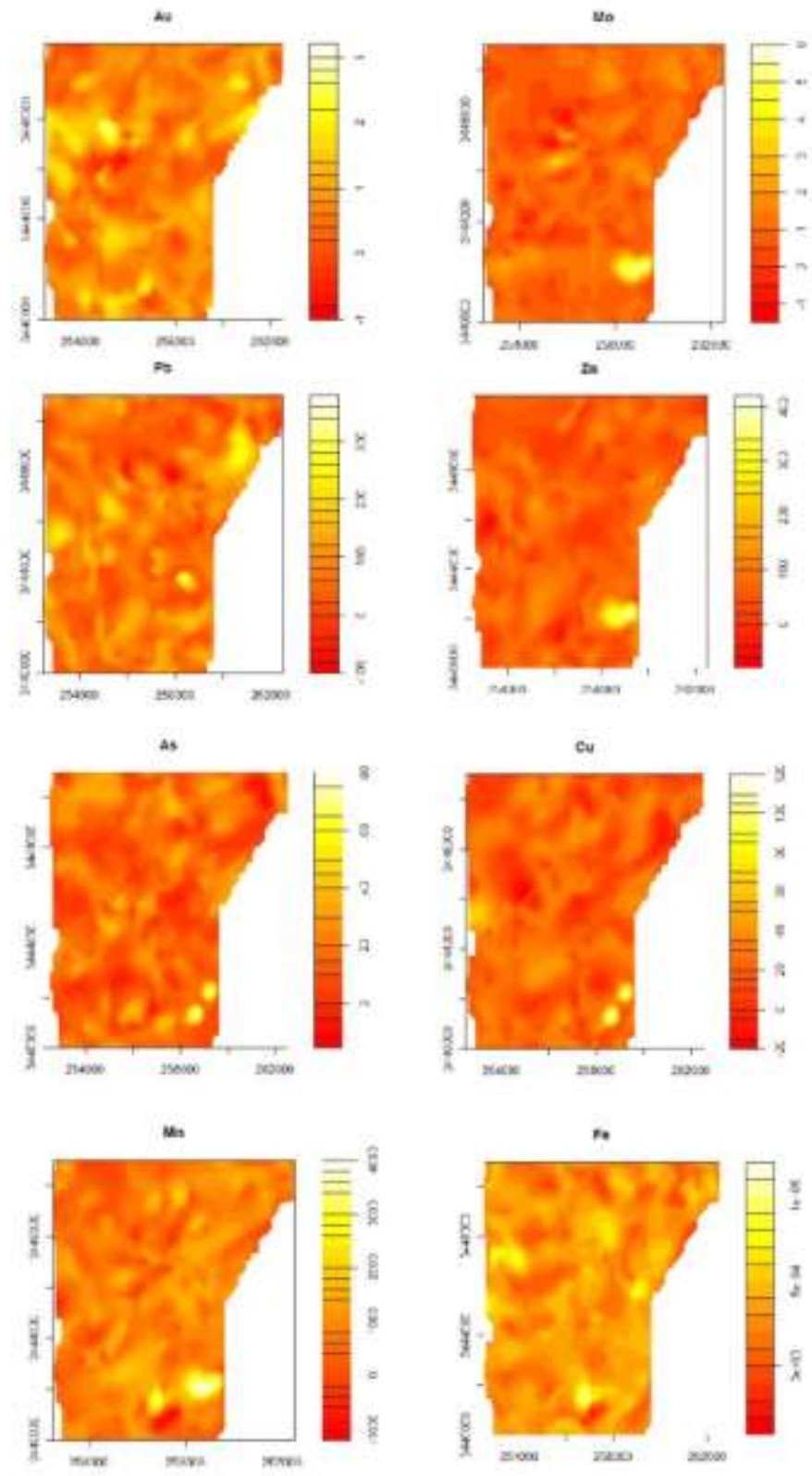

Fig.4: Contour line diagrams for 8 studied elements

This procedure was repeated for different elemental concentrations. The evaluated grades in cells were sorted out based on decreasing grades, and log-log plots were generated for 8 elements (Fig. 5). Break points between straight-line segments in those log-log plots show threshold values separating populations of geochemical concentration values representing geological differences due to distinct geochemical processes. Elemental geochemical populations are delineated in these $\log -\log$ plots. For example figure 5 shows C-A log-log plot for $\mathrm{Au}$ and $\mathrm{Cu}$. There are four geochemical populations for $\mathrm{As}, \mathrm{Fe}, \mathrm{Mo}, \mathrm{Pb}$ and $\mathrm{Zn}$ and five geochemical populations for $\mathrm{Au}, \mathrm{Cu}$, and $\mathrm{Mn}$. Based on the $\mathrm{C}-\mathrm{A} \log -\log$ plot, there are four enrichment phases for As within threshold values equal to $14.15,31.50$ and $73.70 \mathrm{ppm}$ where higher than the last threshold value the extreme As enrichment phase in the study area (Table 2). The population below $28282 \mathrm{ppm}$ and between 32859 and $73130 \mathrm{ppm}$ are the low and moderate phase of Fe enrichment, respectively. In addition, the population of upper than 73130 ppm has a high enrichment phase of Fe in the study area. Moreover, $\mathrm{Cu} \mathrm{C}-\mathrm{A} \log -\log$ plot shows five geochemical populations for this element with threshold values equal to 20 , 28.5, 36.6, and 109 ppm (Table 2). Low and moderate Mn phases are below 812 ppm and between 1408 and 3294 ppm, but high phase has high value of $\mathrm{Mn}$ higher than $3827 \mathrm{ppm}$. Molybdenum has four enrichment phases in the study area based on Mo C-A log-log plot, as depicted in Fig. 5. Their threshold values equaled to $0.77,1.50$ and $4.95 \mathrm{ppm}$. Lower than $0.77 \mathrm{ppm}$ is a low Mo enrichment phase in this area and moderate occurred between 1.50 and $4.95 \mathrm{ppm}$ and population of upper than $4.95 \mathrm{ppm}$ has a high enrichment phase of Mo (Table 2). Figurers 6 to 13 show anomaly map for 8 elements based on the C-A fractal model.
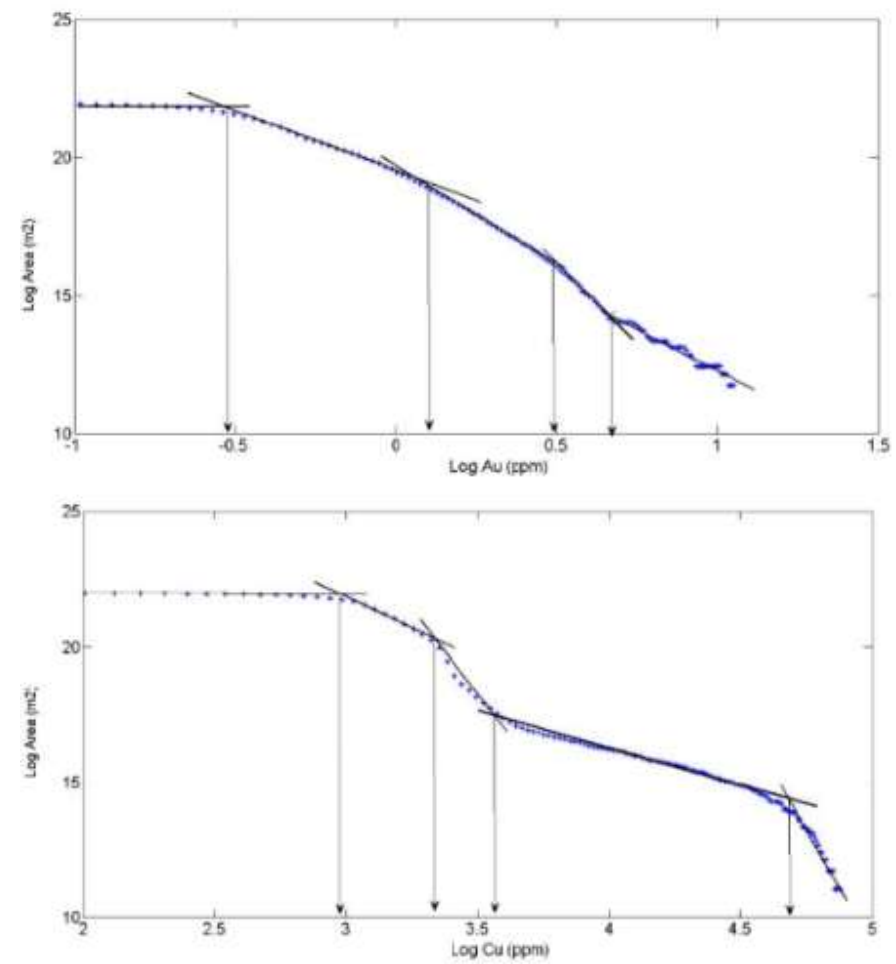

Fig. 5: $\mathrm{Log}-\log$ plots (C-A model) for $\mathrm{Au}$ and $\mathrm{Cu}$

TABLE 2: THRESHOLDS OF C-A MODEL FOR DIFFERENT GEOCHEMICAL ANOMAlies of Au, Cu, Zn, Fe, Mn, Mo, As AND PB

\begin{tabular}{|c|c|c|c|}
\hline \multirow{2}{*}{$\begin{array}{c}\text { Element } \\
(\mathrm{ppm})\end{array}$} & \multicolumn{3}{|c|}{ C-A fractal model } \\
\cline { 2 - 4 } & Low & Moderate & High \\
\hline $\mathrm{Au}$ & 0.60 & 1.16 & 1.65 \\
\hline $\mathrm{Cu}$ & 20.10 & 28.50 & 36.6 \\
\hline $\mathrm{Zn}$ & 61.56 & 121.50 & 284.30 \\
\hline $\mathrm{Fe}$ & 28282.54 & 32859.63 & 73130.45 \\
\hline $\mathrm{Mn}$ & 812.40 & 1408.10 & 3294.47 \\
\hline $\mathrm{Mo}$ & 0.78 & 1.50 & 4.95 \\
\hline $\mathrm{As}$ & 14.15 & 31.50 & 73.70 \\
\hline $\mathrm{Pb}$ & 63.43 & 134.30 & 190.57 \\
\hline
\end{tabular}




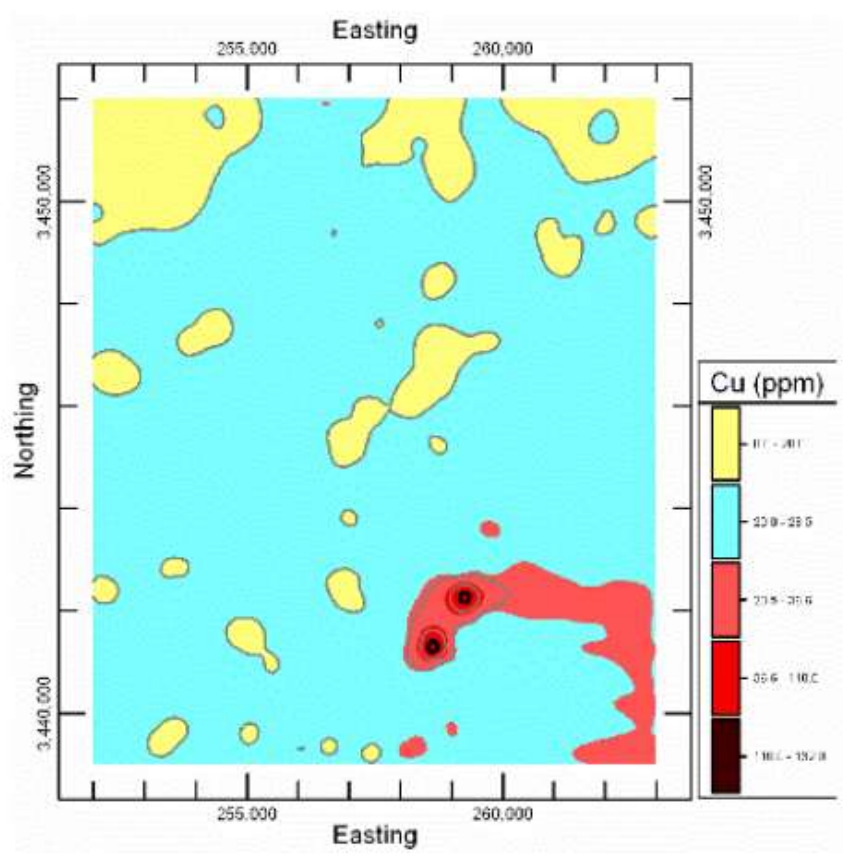

Fig.7: Distribution map of copper using fractal model

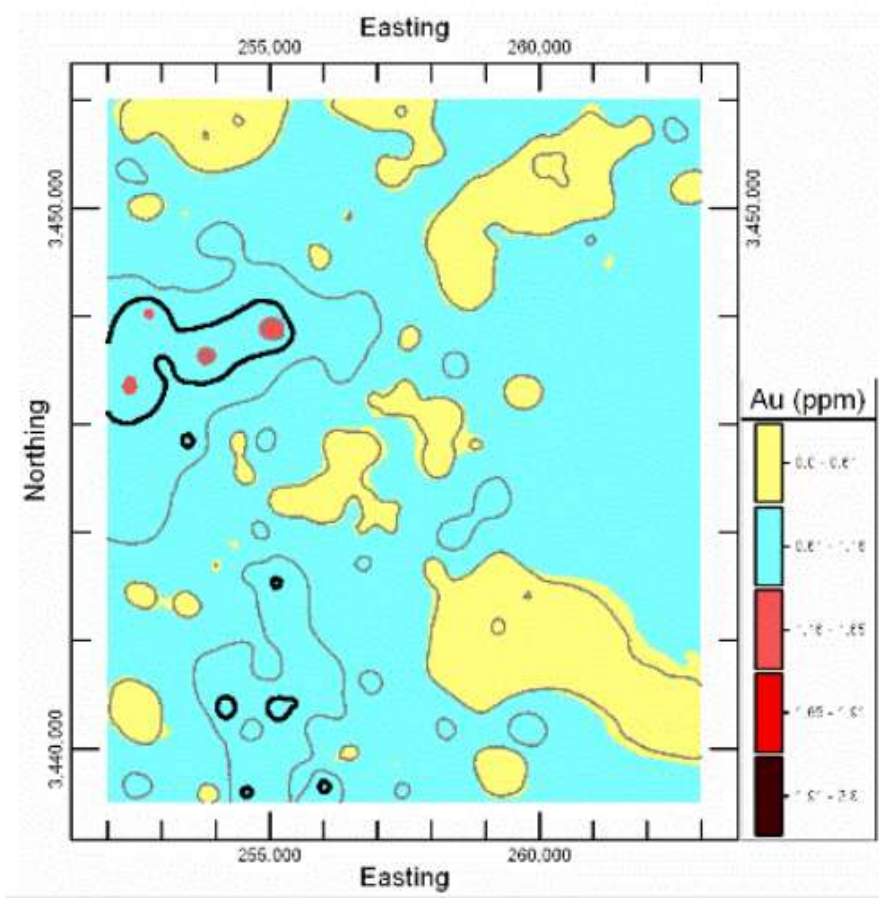

Fig.8: Distribution map of using Gold fractal model

\section{CONCLUSION}

This method is as a filter in geochemical prospecting when attempting to differentiate between samples with high elemental concentrations and those belonging to low elemental concentrations (background). In this study, this method was used for determining the anomalies in studied area. The geochemical maps show the existence of high geochemical concentrations in north, northwest, and center of region for gold and copper. The results of comparing the geochemical map of elements confirmed the correlation between gold, copper, molybdenum, and iron in the region. Additionally, a negative correlation was observed between the arsenic with gold and there isn't any correlation between the elements of gold and copper with manganese, lead, and zinc. Finally, by comparing the results of fractal method, it was observed that using this method can be effective in identifying the overall trend of mineralization in studied area especially in early stages of exploration.

\section{REFERENCES}

[1] Afzal, P., Khakzad, A., Moarefvand, P., Rashidnejad Omran, N., Esfandiari, B., Fadakar Alghalandis, Y., "Geochemical anomaly separation by multifractal modeling in Kahang (Gor Gor) porphyry system, Central Iran", Journal of Geochemical Exploration 104, 34-46, 2010.

[2] Cheng, Q., Agterberg, F.P., Ballantyne, S.B., "The separation of geochemical anomalies from background by fractal methods". J Geochem Explor 51,109-130, 1994.

[3] Cheng, Q., "Spatial and scaling modeling for geochemical anomaly separation", Journal of Geochemical Exploration, 65,175-194, 1999.

[4] Daya, A.A., "Application of concentration-area method for separating geochemical anomalies from background: a case study of Shorabhaji region, northwest of Iran". Arabian journal of geosciences, 8, 3905-3913, 2015 a.

[5] Daya, A.A., "Comparative study of C-A, C-P, and N-S fractal methods for separating geochemical anomalies from background: A case study of Kamoshgaran region, northwest of Iran". Journal of geochemical exploration, 150, 52-63, $2015 \mathrm{~b}$.

[6] Daya, A.A., Afzal, P., "A comparative study of concentration-area (C-A) and spectrum-area (S-A) fractal models for separating geochemical anomalies in Shorabhaji region, NW Iran". Arab J Geosci 8:8263-8275, 2015.

[6] Dimiri, V., "Application fractals in earth sciences": Springer- Verlag, New York, 2000.

[7] Filzmoser, P., Garrett, R.G., Reimann, C., "Multivariate outlier detection in exploration geochemistry". Computers and Geosciences, 31, 5, 579-587, 2005.

[8] Garrett, R.G., "The chi-square plot: A tool for multivariate outlier recognition". Journal of Geochemical Exploration, 32, 1-3, 319-341, 1989.

[9] Goncalves, M.A., Vairinho, M., Oliveira, V., "Study of geochemical anomalies in Mombeja area using a multifractal methodology and geostatistics”. In: Buccianti A, Nardi G, Potenza R (eds) IVIAMG'98. De Frede, Ischia Island, pp 590-595, 1998.

[10] Griffis, R.J., Meixner, H.M., Griffis,A.T., Bondar, W.F, Leitch, C.H.B., "Report on preliminary mineral reconnaissance aest block, East Iran", Geology and Mineral Survey of Iran, 1977-1978.

[11] Heidari, S., Ghaderi, M., Afzal, P., "Delineating mineralized phases based on lithogeochemical data using multifractal model inTouzlar epithermal $\mathrm{Au}-\mathrm{Ag}(\mathrm{Cu})$ deposit", NW Iran. Appl Geochem, 31,119-132, 2013.

[12] Lima, A., De Vivo, B., Cicchella, D., Cortini, M., Albanese, S., "Multifractal IDW interpolation and fractal filtering method in environmental studies: an application on regional stream sediments of Campania region (Italy)". Appl. Geochem. 18, 1853-1865, 2003.

[13] Mandelbrot, B.B., "The Fractal Geometry of Nature (Update and augmented edition) ", Freeman, New York, 468 pp, 1983.

[14] Jimenez-Espinosa, R., Sousa, A.J., Chica-Olmo, M., "Identification of geochemical anomalies using principal component analysis and factorial kriging analysis", Journal of Geochemical Exploration, 46, 245-256, 1993.

[15] Rousseeuw, P. J., Leroy, A. M., "Robust regression and outlier detection". John Wiley and Sons - New York, 1987.

[16] Thomson, M., Howarth, R.J., "A new approach to the Estimation of Analytical precision", Journal of Geochemical Exploraon, Vol.9, 1978 